\title{
Helen Salisbury: Talking about death
}

\author{
Helen Salisbury GP \\ Oxford
}

Any emergency hospital admission of frail, elderly patients means a decision about what to do if their heart stops beating. Should we attempt cardiopulmonary resuscitation (CPR)? The medical answer isn't always clear, and the decision should involve the patient and sometimes relatives. ${ }^{12}$ For the admitting team, it would be useful if that discussion had already taken place with a doctor who knows the patient, with a decision recorded somewhere accessible.

This sounds like common sense, so why aren't GPs routinely discussing end-of-life care with patients who may need it soon? NHS England encourages doctors to engage in care planning conversations, ${ }^{2}$ but these don't always happen.

One of the main challenges is choosing the right time. Some patients are proactive and inform me that they don't want CPR in any event, often making formal advance directives to this effect even when they have many healthy years in prospect.

Although some illnesses have a well known trajectory, for most patients the future is unpredictable. For doctors, the question "Would you be surprised if this patient died in the next 12 months?" is meant to help us think about when the discussion might be relevant. But our surprise (or otherwise) has been shown to be a very poor indicator of the likelihood of death. ${ }^{3}$ I have patients I honestly didn't expect to live long when I first met them 17 years ago, but they're still pottering on. Others decline rapidly, having been stable for years, and the right moment for that discussion is never identified.

Getting it wrong clearly has downsides in a culture where discussing death isn't commonplace. If I raise the issue of resuscitation with my patient she may be happy to have a theoretical discussion about her preferences-or she may conclude that I know something about her health that she doesn't, something that makes me think she's likely to die soon. I must beware of creating unnecessary anxiety and reducing the quality of her remaining life.
Even if I do think that the time is appropriate, and gentle exploration leads me to believe that the patient would be happy to have this discussion, it's not a conversation that can be rushed. In reality, I can't see an invitation to an appointment to discuss end-of-life care going down well, so it's likely to be tagged on to a consultation about something else.

Such conversations are not just about resuscitation but also about where someone would like to be cared for. One barrier to these discussions, identified in research, is the fear of falsely raising expectations. ${ }^{5}$ The community services required for a gentle and dignified death at home may simply not be available when the time comes.

I feel for my hospital colleagues who make difficult decisions in emergency situations-but GPs are doing their best, and there are no easy solutions.

Competing interests: See www.bmj.com/about-bmj/freelance-contributors.

Provenance and peer review: Commissioned; not externally peer reviewed.

1 General Medical Council. Resolving disagreements. 2010. https://www.gmc-uk.org/ethicalguidance/ethical-guidance-for-doctors/treatment-and-care-towards-the-end-of-life/workingwith-the-principles-and-decision-making-models\#paragraph-47.

2 Masters K. My mum's care means that decisions not to resuscitate must now be discussed with patients. BMJ 2017;356:j1084. 10.1136/bmj.j1084 28254811

3 NHS England. Enhanced service specification—avoiding unplanned admissions: proactive case finding and patient review for vulnerable people 2015/16. 2015. https://www.england. nhs.uk/commissioning/wp-content/uploads/sites/12/2015/03/avoid-unplanned-admissions03-15.pdf.

4 Downar J, Goldman R, Pinto R, Englesakis M, Adhikari NK. The "surprise question" for predicting death in seriously ill patients: a systematic review and meta-analysis. CMAJ 2017;189:E484-93. 10.1503/cmaj.160775. 28385893

5 Sharp T, Malyon A, Barclay S. GPs' perceptions of advance care planning with frail and older people: a qualitative study. Br J Gen Pract 2018;68:e44-53. 10.3399/bjgp17X694145. 29255110

Published by the BMJ Publishing Group Limited. For permission to use (where not already granted under a licence) please go to http://group.bmj.com/group/rights-licensing/ permissions 